\title{
Pregnant Women's Perceptions of Anaemia in Pregnancy at the Urban Health Facility in Ahougnansou (Centre-north Côte D'ivoire)
}

Adou Serge Judicaël ANOUA ( $\square$ anoua_08@yahoo.fr)

Alassane Ouattara University

Research article

Keywords: Anaemia, pregnant woman, reproductive risk practice, explanatory model, reproductive health, Côte d'Ivoire

Posted Date: July 2nd, 2020

DOI: https://doi.org/10.21203/rs.3.rs-36763/v1

License: (c) (i) This work is licensed under a Creative Commons Attribution 4.0 International License. Read Full License 


\section{Abstract \\ Background}

Anaemia in pregnancy is an issue of concern in the reduction of reproductive health morbidity in Côte d'Ivoire. This research aimed to describe the meaning of anaemia and analyze its explanatory factors from the perspective of pregnant women in a hospital setting in Ahougnansou in the city of Bouaké in the Centre-North of Côte d'Ivoire.

\section{Methods}

This qualitative research was descriptive-interpretive. Using this approach, individual interviews were conducted with twenty (20) participating pregnant women. The research took place in the hospital environment of Ahougnansou in the city of Bouaké in Côte d'Ivoire. The data were analyzed using a conventional inductive content analysis supported by a thematic grid.

\section{Results}

Perceptions have identified anaemia in pregnancy as a life-threatening reproductive morbidity for both mother and child. Its specific image has been associated with a lack of blood in the body. Symptoms have included fever, dizziness, fatigue, lack of appetite, pallor and thinness. Its aetiology has been attributed to food bans. In addition, the explanatory logics noted its link with irrational health behaviours such as irregular consultations, inaccessibility to edifying advice, lack of early detection, lack of use of daily oral iron and folic acid supplementation, lack of mobilization of financial resources and non-observance of a balanced diet.

\section{Conclusion}

Examination of the social representation of anaemia in pregnancy leads to relevant insights into the irrational health behaviours of pregnant women. On the other hand, the search for appropriate and effective long-term solutions to this reproductive health morbidity requires the immersion of midwives in the living environment of pregnant women and specific community health actions in populations that can be located in space and time in order to circumscribe the reproductive practices involved in resistance to nutritional recommendations in the prenatal period.

\section{Background}

Anaemia is a morbidity of reproductive health concern. The presence of this disease during pregnancy remains a risk basis for the survival of the mother-child couple. Indeed, maternal anaemia increases the risks of loss of physical productivity, termination of pregnancy, maternal death, stillbirth, prematurity, low birth weight and inability to assimilate. As a result, the impact on communities and nations is enormous in terms of reduced economic productivity and development [1]. This dramatic state of affairs points to the issue of anaemia as a major concern for women, children, families, social groups and society as a whole. Increasingly, its reduction is of undeniable importance. As a result, there is a need for global response actions. In line with the recommendations of the World Health Organization, the focus is on nutritional intervention. In this case, daily oral iron and folic acid 
supplementation and communication for a healthy diet are applicable to pregnant women in the context of antenatal care [2]. Similarly, previous research provides some answers about antenatal anaemia. In the current state of knowledge, the factors vary among authors. One of the factors associated with anaemia in pregnancy was socio-demographic. It first concerned age, with a population of young pregnant women under 20 years of age more prone to anaemia [3]. Subsequently, procreative behaviours, in this case pregnancy in multiparous and primiparous mothers, were significantly associated with anaemia before delivery [4]. In addition, there was a significant relationship between certain socio-economic factors and anaemia during pregnancy. These included background, ethnicity [5], household size, household socioeconomic level, female education, and occupational status of the household head [6]. Compared to these socio-demographic indicators, certain parameters in the epidemiological dimension, with reference to chronic pathologies and the history of gestational anaemia, were also presented as factors associated with anaemia in pregnant women [7]. Following the history of chronic pathologies, various factors related to the ethnological dimension were associated with anaemia in pregnant women. In this case, the low iron diet [8] and the lack of supplementation of pregnant women were major risk factors for the development of anaemia during pregnancy [9]. In fact, the analysis of the facts clearly indicates that the factors of anaemia in pregnancy have various dimensions. This issue appears to be a challenge for many scientific disciplines. In particular, the level of anaemia affects only $40 \%$ of pregnant women aged 15-49 years worldwide [10]. Its persistence is increasingly noted with a prevalence of more than $50 \%$ in South Asia, Central Africa and West Africa [11]. In Côte d'Ivoire, according to the Ministry of Health and Public Hygiene in 2016, the proportion of pregnant women with anaemia was $64 \%$, with a maximum prevalence of $66 \%$ in the Centre-North region [12]. In this region, the city of Bouaké is no exception to this prevalence of anaemia in pregnant women, since $30 \%$ of them suffered from it according to the 2018 activity report of the local health district. This high prevalence appears to be a challenge that is in line with the health policy of the Ivorian State. Indeed, under axis 5 of the strategic framework of the National Health Development Plan (PNDS) 2016-2020, it is stipulated that the health of mothers, newborns, children, adolescents and young people is improved by 2020 and mortality is reduced by 50\% [12]. Similarly, the reduction of maternal anaemia in the antenatal period appears to be a major challenge. In the end, it is true that the weight of all these sociodemographic, epidemiological and ethnological factors on the high prevalence of anaemia in pregnant women seems obvious. It is also true that, despite the health measures adopted, its extent in the context of Bouaké requires clarification. From a socio-anthropological perspective, account must be taken of the irrational health behaviours of pregnant women that underlie anaemia during pregnancy. The aim of this article is to describe the meaning of anaemia in pregnancy and to analyse its explanatory factors from the point of view of pregnant women with a view of contributing to the control of this disease in the prenatal period. This research was conducted using a variety of appropriate methods.

\section{Methods}

\section{Sampling and data collection}

The geographical research unit selected was the Ahougnansou urban health facility for its apparently high level (20\%) of anaemic pregnant women screened for ANC according to the 2018 activity report of the Bouaké NorthWest health district. The basis for the choice of this first-contact health facility was the need to describe the meaning of anaemia in pregnant women having immediate contact with reproductive health services. The choice of site for our research was the maternity ward. This health space had one (01) prenatal consultation room, three (03) delivery beds, and ten (10) hospitalization beds for twelve (12) midwives assisted by ten (10) health care assistants. While the prenatal consultation was free, the prenatal check-up including biological and ultrasound 
examinations amounted to approximately 25,000 FCFA for the follow-up of a normal pregnancy. Pregnant women interviewed at the Ahougnansou urban health facility had special and frequent needs in view of the high cost of pregnancy monitoring. This could, however, influence compliance with nutritional recommendations and increase the risk of anaemia in the prenatal period. Therefore, it is important to present this type of research.

This qualitative research was descriptive and interpretative [13]. It was carried out from the perspective of social anthropology over a period of one week, from 7 to 14 October 2019. The approach used proved to be appropriate for understanding the meaning of anaemia during pregnancy and its explanatory factors, paying attention to the opinions of pregnant women. More precisely, it allowed to highlight a set of subjective elements, revealing significant images and meanings that represented the perceptions that pregnant women, in the context of the urban health training of Ahougnansou, have of anaemia in the prenatal period. This concern leads us to shed light on the survey population.

Pregnant women attending antenatal consultations at the maternity ward of the Ahougnansou urban health facility were surveyed during the research period. They were all chosen because they were the social group in difficulty likely to benefit from the results of the approach, and because they were aware of anaemia and would contribute to the description and explanation of its various meanings and contributing factors. The survey of pregnant women in prenatal care was an individual survey. To participate in the research, women had to be knowledgeable about anaemia, speak French and be willing to share their perceptions of the disease. These selection criteria would provide significant information about thoughts about anaemia during pregnancy. Exclusion criteria were ignorance of anaemia and inability to understand and express themselves in French, and lack of desire to participate in the research. The survey population identified in this way uses the procedure of selecting individuals and their numbers.

A convenience sample was used to select pregnant women who met the established inclusion criteria. These women were selected for research after obtaining their verbal consent for a sufficiently comprehensive, realistic and contextualized [13] description of the meaning of prenatal anaemia. Thus, given these principles, the number of participants could not be determined in advance. However, we plan to interview thirty (30) pregnant women in order to reach an acceptable level of information saturation. As a result, we met with twenty (20) pregnant women and stopped the interviews afterwards. This logic was justified since the four (04) new interviews conducted after this number of women did not provide any new information compared to the previous ones. Furthermore, the field strategy took into account ethical considerations.

A protocol order was the starting point for the investigations. To this end, we initiated an administrative procedure in order to inform the authority of the Ahougnansou urban health training of the scientific intention of the research. From this administrative procedure, an authorization for research within the said structure was granted to us by the person in charge. In the same way, we obtained the consent of the pregnant women participating in the survey based on a clarification of the purpose and conduct of the research. Furthermore, we made a point of honour of the confidentiality of the information to be collected as well as the anonymous nature of its analysis. This made it possible to use a number for each participant and to establish a bond of trust between the participants and us as researchers. The question now arises as to how the survey itself was conducted in the field.

Individual interviews were conducted with pregnant women involved in this research. As support, a semi-directive interview was conducted using a guide with open-ended questions such as "What do you think about when talking about anaemia during pregnancy?" "What do you think are the factors that promote anaemia during pregnancy?" 
"What do you see as the link between anaemia and poor prenatal care?" "How can these links be explained?".

These questions focused more on the knowledge of the disease and these explanatory factors by pregnant women who expressed their opinions in each interview. This was intended to describe the meaning of anaemia in the prenatal period and to capture the explanatory values highlighting the influence of irregular prenatal visits on the prevalence of this morbidity during pregnancy. In addition to this first level of questioning, in-depth questions were added during the interview, such as "Can you tell me more", "What do you mean by...? What do you mean by...?", "Under what circumstances...?". This second level of questioning consisted more of fostering understanding of the thoughts of the pregnant women interviewed with regard to their perspectives. At the time of starting the information collection, we had supported, with the assistance of the midwife major, a ten (10) minute discussion with the women consenting to the survey. This made it possible to present the objectives and context of the research and to verify their understanding of the content of the questions. Interviews were conducted every day of prenatal visits in a room adjacent to the prenatal waiting room, prior to routine midwifery examinations. Interviews were digitally recorded for 45 minutes to ensure the integrity of the data collected. As the conversations progressed, the views expressed by each participant were validated with them. The content of each interview was systematically transcribed at each meeting. At the end, we expressed our gratitude to each participant for their collaboration and contribution to this research. This investigative phase was followed by data processing and analysis.

\section{Data management and analysis}

The processing of the data collected was based on a manual analysis inspired by the work of Miles and Huberman (2003) [14]. To condense the data [15], we listened to and transcribed verbatim the recordings of all the conversations, and then we reread the note-taking. We then translated the verbatims into complete sentences in order to better understand their context, before identifying the significant extracts. This process enabled us to develop a global vision of the views of the pregnant women interviewed and to ensure that the detailed ideas were recorded on a summary sheet. Following this, we made an inventory of the themes that emerged. Based on a content analysis [16], we highlighted the categories structured around the ideas of perception, social determinants and explanatory logic to give meaning to anaemia during pregnancy according to the pregnant women interviewed at the Ahougnansou urban health facility. In addition, we continued this phase of structuring the information by theme by organizing the presentation in a logical order of relevant facts, statements so as to support our sections on knowledge benchmarks, explanatory factors of pregnant women about anaemia during pregnancy. In order to convince ourselves of our understanding of this issue, we ensured that the information from interviews validated during data collection was well linked to the corresponding idea we were putting forward. It is from these conclusions that we have grasped the significance of the views expressed by the pregnant women interviewed on the issue of anaemia in the antenatal period.

\section{Results}

The results of this research present the social perceptions and explanatory factors related to anaemia among pregnant women interviewed at the Ahougnansou urban health facility in the city of Bouaké, Côte d'Ivoire.

\section{Social perceptions of anaemia in pregnant women}

The pregnant women interviewed considered anaemia as a blood-related illness. For the participants, 
In their view, a person with anaemia was someone who had a lack of blood in their body. This physiological expression revealed disturbances in the physical body of pregnant women with anaemia. The presence of these disturbances was primarily marked by expressive signs. One participant spoke of signs of manifestations of anaemia during pregnancy, including fever, dizziness, fatigue, lack of appetite:

"It can manifest itself in the body heating up a lot, the person sweating a lot, and the eyes turning. When she has this, you can also see that the pregnant woman never eats much but sleeps too much because she works a lot without rest." (Participant 10).

In addition, other signs of anaemia in the pregnant woman included pallor of the face, eyes, palm, sole of the foot and thinness. As one participant said:

"You can tell a pregnant woman who is anaemic when there is a change in skin tone, she becomes very pale, her eyes are not coloured, the soles of her feet and fingers are whitish. She often becomes desperate."(Participant 16).

For them in particular, the pallor would represent the stage of severity in the evolution of this condition. From these facts called symptoms, etiological theories were derived. Pregnant women interviewed attributed the supposed causes of anaemia to a lack of variety in diet, as one participant reported:

"I think that when you are pregnant and then you eat "attiéke" only, you think it's the only food in the world, or when you always eat the same food, it's normal that you don't have a lot of blood." (Participant 20).

In addition, the pregnant women interviewed also felt that the onset of anaemia could be due to unbalanced food, as one participant said,

"It is the food that causes anaemia. Foods such as yams, rice without sauce, these foods do not contain iron. In a word, the diet is unbalanced." (Participant 1).

Diet therefore remained a major cause of anaemia during pregnancy. The issue of imbalance in the diet of the pregnant woman during the prenatal period was related to compliance with the dietary prohibitions of the custom of belonging, as one participant revealed:

"At home when you're pregnant, your mother reminds you not to eat papaya and coconut because your feet and breasts will swell, beans because of bloating, okra because of itching, and bush meat because of the diseases and some of their characteristics that the child may take after delivery. It is because we sort food because of custom that we eat what is not rich in iron and causes anaemia." (Participant 18).

It was clearly stated here that food bans were highlighted as the cause of anaemia. Based on these nosological, symptomatological and etiological facts, most of the pregnant women interviewed described this disease as dangerous because it is fatal, as one participant said:

"When we talk about anaemia, I automatically think of death. Anaemia kills quickly, it's really dangerous." (Participant 7).

Anaemia was identified as a specific threat in the prenatal period. They emphasized the health risks for mother and child during pregnancy, as one participant put it: 
"I think it is serious, because if mother is sick, baby in the womb will get sick too." (Participant 3).

Similarly, the anaemic pregnant woman was predisposed to risks that could not only be fatal for her but also for the foetus during delivery, as illustrated by one participant's comment:

"It can be complicated for the pregnant woman who is anaemic during delivery, I think her delivery will be fatal." (Participant 12).

The risks involved in this situation actually heightened the seriousness of this illness and raised strong emotions of fear in pregnant women, as one participant pointed out:

"I'm really scared for her, when you don't have enough blood you can die or lose the baby during pregnancy or delivery." (Participant 14).

From this knowledge of the pregnant women interviewed, social perceptions about anaemia during pregnancy emerge. This foundation of the social dimension of anaemia remains essential in determining the rationales for its prevalence in the prenatal period among the pregnant women interviewed.

\section{The explanatory logic of anaemia in pregnancy in pregnant women}

Pregnant women interviewed suggested that irregular prenatal visits were related to anaemia during pregnancy. This was due to the fact that pregnant women did not attend prenatal appointments as often as necessary. This practice influenced the early detection of anaemia during pregnancy, as one participant noted:

"Coming to the hospital is one way to find out what health problems a pregnant woman may have in order to provide treatment or advice on how to deal with them, but staying at home is not going to tell if she is anaemic and to monitor the pregnancy well." (Participant 19).

This was like saying that not attending antenatal visits does not give them access to edifying advice about anaemia. These behavior change communications were far from reaching some pregnant women who were still resistant to regular prenatal care. As one participant said in the interview,

"We pregnant women neglect antenatal visits very much. Because of this, we are not really aware of important messages against anaemia and other problems during pregnancy." (Participant 8).

As a result, they remained unaware of the messages carried by midwives during prenatal consultations on the issue of anaemia, for the well-being of the mother and her unborn baby. According to one participant:

"When you are not aware of anaemia, the blood medication we are prescribed and the food the pregnant woman needs to eat so that we and our baby are healthy, this is what makes it impossible to be aware and take precautions to avoid this disease." (Participant 17).

This neglect to provide information about anaemia in pregnancy exposes women willingly to this morbidity. Moreover, the absence of pregnant women from awareness messages on anaemia during prenatal consultations undeniably accentuated the lack of use of daily oral iron and folic acid supplementation recommended by midwives at the health facility. This irresponsibility was completely consistent with the fact that pregnant women developed a fearful conception of the side effects of iron supplements. One participant illustrated this as follows: 
"I can't stand blood medication. The smell there really makes me tired. When I take them, I vomit and often I feel weak like that. It's not even worth it, because as soon as I put them in my mouth, they automatically come out. So I don't even want to take them." (Participant 13).

This fear, accentuated by the lack of information on anaemia, was also conducive to the failure to mobilize financial resources for iron and folic acid supplementation, as one participant confided:

"When I am pregnant, I eat a lot of leaves because they give a lot of blood. It's good because always, always hospital, it can't go, because there is no money. When it's like that, I do indigénat instead of taking blood medicine." (Participant 19).

Similarly, the absence of pregnant women from the anaemia behavior change communication during prenatal visits naturally accelerated compliance with dietary bans during pregnancy. These restrictions were criteria for normal dietary practices erected by custom in the prenatal period. This logic was part of the breakdown in the observance of a balanced diet that causes anaemia during pregnancy, as one participant mentioned:

"At home, to avoid the wrath of the geniuses, we forbid you to eat meat and fruit. It's because we totally respect that instead of knowing the midwife's advice that we don't have a lot of blood during pregnancy." (Participant 2).

All of these factors related to anaemia in pregnant women require consideration of social relevance in order to induce changes in the provision of antenatal care and to help reduce the vulnerabilities of pregnant women. This body of evidence deserves to be illuminated.

\section{Discussion}

This set of findings informs the perceptions and explanatory logic of the pregnant women interviewed regarding anaemia in pregnancy. However, our sample of pregnant women $(n=20)$, although heterogeneous, did not predetermine the characteristics of the participants. This made it impossible to identify the sociodemographic profile of the respondents when analyzing the data collected. This reflects an analytical bias if we take into account the plausible discovery of multiple realities in the participants' perspectives on meaning.

Notwithstanding this bias, this research has shed light on the perceptions that the pregnant women interviewed had of anaemia in pregnancy. These were the supports from which the participants developed an area of knowledge. The benchmarks of this knowledge were identified at several points. The nosological framework revealed that the pregnant women surveyed reflected the specific image associated with anaemia in pregnancy with insufficient blood in the body, as shown in other studies [17]. For them, this unique form was associated with a negative image. By emphasizing this physiological dimension, they recognized anaemia in pregnancy as a reproductive morbidity, as has been recognized by biomedical science. In the minds of the pregnant women interviewed, anaemia in pregnancy thus represented a danger to the mother and the foetus. They explained this by the morbid aspects of this disease which they did not seem to be unaware of. The symptomatology highlighted in the present work was translated by several forms of manifestation of the disease. These are: fever, vertigo, fatigue, lack of appetite, pallor and thinness as other studies have recognized [17]. These different states of morbidity were considered by these studies as risk cases since they endangered the life of the mother and the child. The symptoms identified were limited to bodily manifestations of the disease. This conception of the morbid states of anaemia in pregnancy specific to the pregnant women interviewed appeared limited. They seemed to be unaware that medical science carries out rigorous biological tests, such as hemoglobin electrophoresis and blood counts, 
which can provide accurate information on hemoglobin levels, mean blood cell volume and mean corpuscular hemoglobin concentration. Indeed, the assessment of hemoglobin was almost always considered in a martial deficiency assessment only in cases of anaemia [18]. These biological data also represent other forms of anaemia in pregnancy [19]. Following this characterization, the social aetiology of anaemia in pregnancy was discussed. According to the pregnant women, the supposed causes were food bans and their corollaries of an unhealthy and unbalanced diet. In addition to inadequate nutrition, malaria and iron deficiency have been systematically cited as causes of this morbidity in the light of the results of other studies [20]. This practice of a psychosocial nature continued to perpetuate original conceptions and mechanisms in terms of culturally appropriate responses to prenatal nutrition for pregnant women. This resulted in a level of risk related to the lack of nutrition and thus the onset of anaemia. The observance of these dietary prohibitions is controlled by an attitude of adherence of pregnant women to the experiences of elderly mothers, which has become the norm in terms of nutrition during pregnancy [21]. The socio-cultural environment of pregnant women remained resistant to the process of change in maternal and child health. As a result, pregnant women did not have sufficient ownership of daily oral iron and folic acid supplementation [7] and communication for healthy eating during pregnancy. The causes cited were mainly socio-cultural. The medical and behaviour change communication backgrounds of the pregnant women interviewed were not well known. These reference points of perception were supported by an examination of the basis of anaemia in pregnancy. These indications induce an explanatory logic.

This research has highlighted irrational health behaviours in the face of prenatal anaemia. Indeed, the pregnant women interviewed noted that irregular prenatal visits were linked to anaemia in pregnancy. This finding is all the more justified in that other studies have highlighted the fact that the high number of ANCs in health facilities has been associated with a low prevalence of anaemia [6]. Conversely, in the context of this research, the absence of pregnant women from antenatal consultations was detrimental to access to edifying advice in the face of this morbidity. This high-risk reproductive practice contributed to a propensity for irrational health behaviours among participants. This was justified by the fact that the pregnant women interviewed noted in these circumstances their lack of early detection of anaemia in pregnancy, their lack of use of daily oral iron and folic acid supplementation and their lack of mobilization of financial resources for the purchase of these supplementation products and, finally, their failure to follow a balanced diet. That said, the irregularity of prenatal consultations was a problem to be resolved in the face of anaemia in pregnancy. This reproductive health morbidity was not only related to the biological factor alone. The human component remained a determining factor in this area. Indeed, it showed the relevance of risky reproductive practices as causal factors of anaemia in pregnancy. It is from the observation of this human dimension that it is possible to highlight the matrices of openness or resistance to nutritional interventions and generic communications about anaemia in pregnancy, with a view of producing a positive impact in pregnant women in the face of this morbidity. Such an approach recommends the immersion of the midwife in the socio-cultural environment of pregnant women, with a view to first exposing the various problem behavioural points. It is by paying particular attention to reducing these behavioural risk factors through the education of pregnant women that the desired change in the response to anaemia in pregnancy can be achieved.

If it is accepted that the human factor is an explanatory factor in the face of anaemia in pregnancy, it seems important to address the issue of this morbidity in a dynamic diagnostic aim requiring intervention. In this way, the emphasis is above all on the awakening of consciousness. This activity should bring together the target of intervention at the level of a health sector in order to reflect on the causes of anaemia and their possible responsibility as well as solutions over time. As a result of this awareness raising session, participants decide to organize the actions to be taken. In this case, promotional activities against anaemia in pregnancy involve social 
mobilization and participation as well as behaviour change communication. In this particular context, those affected by the situation not only agree to take part in the activities, but also become directly involved in the decision-making process, the definition of objectives and the planning of activities, including the monitoring and evaluation plan. This participatory logic should be seen as a guarantee of effectiveness in the response to anaemia in pregnancy.

\section{Conclusion}

Examination of the social representation of anaemia in pregnancy leads to relevant insights into the irrational health behaviours of pregnant women. Anaemia in pregnant women should not be thought of in terms of the curative and the organic. The social and mental dimensions influence the health of pregnant women in the same way as the physical. Anaemia is a health problem to be observed in the socio-cultural environment that underlies it. Human behaviour is an essential underlying factor. On the other hand, the search for appropriate and effective long-term solutions to this reproductive health morbidity requires midwives to be immersed in the living environment of pregnant women. This involves learning the anthropological approach to midwives in order to strengthen their skills through an added value linked to the mastery of the socio-cultural environment. Increasing the midwife's professional performance is a guarantee of efficiency. In the same way, specific community health actions in populations that can be located in space and time appear indispensable in order to circumscribe the reproductive practices involved in resistance to nutritional recommendations in the prenatal period.

\section{Declarations}

Abbreviations

Not applicable for that section.

Ethics approval and consent to participate

Ethical approval was provided by the Research Ethics Board of Alassane Ouattara University, Côte d'Ivoire.

Research Ethics Board of Alassane Ouattara University, Côte d'Ivoire reviewed and approved the procedures used to obtain verbal informed consent from participants and approved that no written consent from participants would be required in addition to verbal consent. Because of its descriptive-interpretive nature, this type of research not require further ethical approval in Côte d'Ivoire. The data collected are anonymized and cannot be related to individual participants.

Consent for publication

Not applicable for that section.

Availability of data and materials

Not applicable for that section.

Funding

This work was supported by ourselves. 
Author contributions

The author contributed to the design, collection, analysis and interpretation of the research data. The author also contributed to the writing of the article and critically reviewed the content before approving the final version.

Acknowledgements

The author would like to express his gratitude to the participating pregnant women for their contribution to the present research and the many hours devoted to this work. He also thanks the urban health facility responsible of Ahougnansou and the midwives for their disponibility and collaboration during the data collection period.

Competing Interest

The author declare no conflicts of interest

\section{References}

1. World Health Organization. Global nutrition targets 2025: anaemia policy brief. Genève: World Health Organization; 2017 (WHO/NMH/NHD/14.4). Licence: CC BY-NC-SA 3.0 IGO.

https://apps.who.int/iris/bitstream/handle/10665/255725/WHO_NMH_NHD_14.4_fre.pdf?ua=1 (accessed April 4, 2020).

2. World Health Organization. WHO Recommendations on antenatal care for a positive pregnancy experience. Genève: World Health Organization; 2017. Licence: CC BY-NC-SA 3.0 IGO.

https://apps.who.int/iris/bitstream/handle/10665/259584/9789242549911-fre.pdf?ua=1 (accessed April 4, 2020).

3. Likilo Osundja J, Alworonga O, Katenga B, Komanda L. Pregnant women's prevalence of anemia in kisangani, Democratic Republic of Congo. International Journal of Innovation Applied Studies. 2018;25(1):294-9. http://www.ijias.issr-journals.org/abstract.php?article=IJIAS-18-105-20.

4. Adebo AA, Yessoufou AG, Médégnonmi C, Kpanou MBB, Soumanou MM, Sezan A. Anémie et facteurs associés chez les gestantes reçues en consultation au Centre de Santé d’Ekpè (Sud du Bénin). Antropo. 2018;40:35-41. .

5. Sass S, Mohamed MS, Zein A, Elberae A, Khadmaoui A, Khllayoun S, Bengueddour R. Relation Entre Les Facteurs Socio-Économiques Et L'anémie Au Cours De La Grossesse (Nouakchott-Mauritanie). European Scientific Journal. 2017;13(36):93-101. http://dx.doi.org/10.19044/esj.2017.v13n36p93.

6. Nikiéma L, Vocouma A, Sondo B, Martin-Prével Y. Déterminants nutritionnels de l'anémie chez la femme enceinte et issue de la grossesse en milieu urbain au Burkina Faso. Revue Science et technique, Sciences de la santé 2010; 33(1 et 2) : 53-68.

7. Tchente CN, Tsakeu EN, Nguea AG, Njamen TN, Ekane GH, Priso EB. Prevalence and factors associated with anemia in pregnant women attending the General Hospital in Douala. The Pan African medical journal. 2016;25:133. doi:10.11604/pamj.2016.25.133.10610.

8. Ouzennou N, Tikert K, Belkedim G, Jarhmouti F, Baali A. Prevalence and social determinants of anemia in pregnant women in Essaouira Province, Morocco. Santé Publique. 2018;30(5):737-45.

doi:10.3917/spub.186.0737.

Page $11 / 12$ 
9. AFIFI O. Anémie et Grossesse. Thèse de médecine. Université Mohammed v-rabat; 2019.

http://ao.um5.ac.ma/xmlui/bitstream/handle/123456789/17441/M2512019.pdf? sequence=1\&isAllowed=y (accessed April 4, 2020).

10. Branca F, Mahy L, Thahira Shireen M. The lack of progress in reducing anaemia among women: the inconvenient truth. Bulletin of the World Health Organisation. 2014;92:231.

doi:http://dx.doi.org/10.2471/BLT.14.137810.

11. World Bank Group. Prevalence of anemia among pregnant women. World Health Organization, Global Health Observatory Data Repository/World Health Statistics.

https://donnees.banquemondiale.org/indicateur/SH.PRG.ANEM (accessed April 4, 2020).

12. Ministère de la Sante et de l'Hygiène Publique (MSHP). 2016, Plan national de développement sanitaire 20162020. République de Côte d'Ivoire, Draft Consolidé, Abidjan.

https://www.childrenandaids.org/sites/default/files/2017-11/pnds_2016-2020.pdf (accessed April 4, 2020).

13. Thorne SE. Interpretive Description. Walnut Creek: Left Cost Press; 2008.

14. Miles MB, et Huberman MA. Analyse des données qualitatives. $2^{e}$ éd. trad. de M.H. Rispal. Bruxelles: De Boeck; 2003.

15. Miles MB, Huberman MA, et Saldaña J. Qualitative Data Analysis. A Methods Sourcebook. $3^{\mathrm{e}}$ éd. Thousand Oaks: Sage Publications; 2014.

16. Paillé P, et Mucchielli A. L'analyse qualitative en sciences humaines et sociales. $2^{\mathrm{e}}$ éd. Paris: Armand Colin ; 2010.

17. Sourbier D. Analyse situationnelle des interventions de lutte contre l'anémie au Burkina Faso, Mémoire Master 2 Sciences, Technologies, Santé. Université Montpellier 1 - Université Montpellier 2; 2013.

https://nutripass.ird.fr/content/download/258282/3958024/version/2/file/M\%C3\%A9moire+finalis\%C3\%A9++Delphine+Sourbier.pdf (accessed April 27, 2020).

18. Belkaid R, Benakli M, Hammoudi-Bendib N, Ramdani-Bouguessa N, Mahi L. Perception of doctors in different specialties of iron deficiency and iron deficiency anemia in Algeria in 2016: the SUPFER DZ survey. The Pan African medical journal. 2019;33:48. doi:10.11604/pamj.2019.33.48.15114.

19. Demmouche A, Moulessehoul S. Prévalence de l'anémie ferriprive au cours de la grossesse dans la wilaya de Sidi Bel Abbes (Ouest de l'Algérie). Antropo. 2010;21:39-48. .

20. Guindo S. Pronostic materno-foetal de l'anémie associée à la grossesse dans le service de gynéco-obstétrique du CSREF de Bougouni. Thèse de médecine. Université des Sciences, des Techniques et des Technologies de Bamako; 2015. https://www.bibliosante.ml/bitstream/handle/123456789/915/15M285.pdf? (accessed April $27,2020)$.

21. Anoua ASJ. Logiques de l'observance des interdits alimentaires en matière de surveillance prénatale chez les gestantes de Kongodékro (Côte d'Ivoire). International Journal of Multidisciplinary Research Development. 2017;4(8):237-41. . 